\title{
TRAÇADO URBANO E SUA INFLUENCIA NO MICROCLIMA: UM ESTUDO DE CASO EM CENTRO HISTÓRICO
}

\author{
Fernanda Miguel Franco \\ Doutoranda do Programa de Pós-Graduação em Física Ambiental, Linha de Pesquisa: Análise Microclimáticas em \\ Sistemas Urbanos, E-mail: fermifran@hotmail.com \\ Marta Cristina de Albuquerque Nogueira \\ Professora do Departamento de Arquitetura e Urbanismo e do Programa de Pós-Graduação em Física \\ Ambienta, Linha de Pesquisa: Análise Microclimáticas em Sistemas Urbanos, E-mail: mcjanp@gmail.com

\section{Osvaldo Borges Pinto Júnior} \\ Professor do Programa de Pós-Graduação em Física Ambiental, Linha de Pesquisa: Análise Microclimáticas \\ em Sistemas Urbanos, E-mail: osvaldo.borges@gmail.com

\section{Marcelo Sacardi Biudes} \\ Professor do Instituto de Física/ IF/ UFMT, Professor do Programa de Pós-Graduação em Física Ambiental, Linha de \\ Pesquisa: Análise Microclimáticas em Sistemas Urbanos, E-mail: marcelo.biudes@gmail.com

\section{José de Souza Nogueira} \\ Professor do Departamento de Física e Coordenador do Programa de Pós-Graduação em Física Ambiental, E-mail: \\ nogueira@ufmt.br
}

\section{http://dx.doi.org/10.5902/223611707697}

\section{RESUMO:}

Cuiabá é uma cidade localizada na região centro-oeste do Brasil, sua colonização ocorreu no início do século XVIII e seu desenho urbano apresenta características da influência arquitetônica de seus colonizadores portugueses. A concepção empírica do traçado da cidade, apesar de não ter como premissa os conceitos da bioclimatologia, em muitas práticas tira partido das condições climáticas para criar uma arquitetura adaptada ao clima local. O objetivo deste trabalho é fazer uma analise buscando identificar características urbanísticas ligadas à bioclimatologia na concepção do traçado citadino vernacular de Cuiabá, discutindo sobre suas conseqüências no conforto urbano e no planejamento da cidade na escala do pedestre. Para isso foram realizados levantamentos iconográficos no centro histórico, em conjunto com uma pesquisa bibliográfica na área de clima urbano que envolve a localidade estudada e um levantamento de dados micrometeorológicos. Como resultado o trabalho termina por identificar ações possíveis para auxiliar as cidades a se tornarem mais adaptadas as características climáticas locais.

Palavras-chaves: Centro histórico, clima urbano, conforto.

\section{ABSTRACT:}

Cuiabá is a city in central-western Brazil, its colonization occurred in the early eighteenth century and its urban design features architectural features of the influence of its Portuguese colonizers. The design of empirical layout of the city, despite not having as premise the concepts of bioclimatology in many practice takes advantage of the weather to create an architecture adapted to the local climate. The objective of this study is to analyze in order to identify 
characteristics related to urban design in bioclimatology Stroke vernacular city of Cuiabá, discussing its consequences in urban comfort and city planning in the pedestrian scale. For this iconographic surveys were conducted in the historic center, together with a literature search in the area of urban climate that involves the locality studied and a survey of micrometeorological data. As a result the paper ends by identifying possible actions to help cities become more adapted to the local climate characteristics.

Keywords: Central history, urban climate, comfort.

\section{INTRODUÇÃO}

$\mathrm{Na}$ construção civil, o uso das novas técnicas construtivas, associado ao uso indiscriminado dos recursos naturais, conduziu à substituição da prática da arquitetura vernácula, atribuindo a solução de todos os problemas construtivos às inovações tecnológicas. Através da história grande parte dos princípios básicos de construção foram sendo substituídos, seja por interesses econômicos, na busca por uma produção em escala, ou estéticos. Estes novos sistemas construtivos muitas vezes não eram adequados ao clima local e, para amenizar o desconforto resultante no interior dos ambientes, buscou-se introduzir soluções, tais como sistemas de iluminação e climatização artificiais, levando a um aumento no consumo de energia dos edifícios.

A arquitetura bioclimática tem sido a solução que muitos estudiosos apontam como estratégia de mitigação dos efeitos climáticos sobre o ambiente urbano e a edificação. A associação entre clima e ambiente construído tem sido tratada desde a arquitetura antiga. Vitruvius escreveu a obra clássica traduzida por Poliâo (1999), alertanto sobre as diferentes necessidades climáticas de cada região. Afirmava ser necessário desenvolver tipos de edificações de um jeito no Egito, de outra forma na Hispânia, ainda diferentemente em Pontus, bem como em Roma e assim por diante de acordo com as propriedades distintas de cada terra e região.

No continente americano a preocupação com o clima é mencionada desde a implantação das primeiras cidades no período da colonização. A concepção do espaço urbano neste período nem sempre é fruto de um planejamento prévio, no entanto é possível notar que as cidades concebidas ao acaso possuem um misto de erros e acertos no que diz respeito à adequação climática. Traços de adaptação ao clima também são relatados por Freire (1992), quando apresenta a adaptação da arquitetura dos portugueses ao Brasil. Segundo o autor os colonizadores tiveram de solucionar o problema do excesso de luminosidade e de calor característico da maioria das cidades brasileiras.

Cuiabá, localizada na região centro-oeste do Brasil, é uma cidade do início do século XVIII, com um desenho urbano de ruas tortuosas e estreitas, topografia acidentada, becos, largos e praças, desenho urbano característico da influência arquitetônica de seus colonizadores portugueses. Esta herança pode ser observada no traçado que se deixava guiar pela natureza, explorando a topografia e deixando que as aglomerações crescessem livremente, sem nenhum esquema pré-concebido. As casas eram implantadas sobre o alinhamento das ruas sem recuos frontais ou laterais, inicialmente o pé-direito era baixo, e as fachadas estreitas reproduziam um único padrão.

De acordo com Freire (1988), o repertório da linguagem arquitetônica cuiabana está impregnado pela paisagem, pelas ruas, as casas, o cotidiano e o modo de vida, historicamente estruturados e organizados através de um lento processo de evolução urbana. $O$ espaço produzido reflete, nas curvas da malha urbana, a ondulação do relevo e a sinuosidade dos rios. 
O objetivo deste trabalho é fazer uma analise buscando identificar características urbanísticas ligadas à bioclimatologia na concepção do traçado citadino vernacular de Cuiabá, discutindo sobre suas conseqüências no conforto urbano e no planejamento da cidade na escala do pedestre. Para isso foram realizados levantamentos iconográficos das edificações e traçado urbano do centro histórico da cidade de Cuiabá-MT em conjunto com uma pesquisa bibliográfica na área de clima urbano que envolve a localidade estudada e um levantamento de variáveis micrometeorológicas como temperatura do ar, umidade relativa e velocidade do vento. Como resultado o trabalho termina por identificar ações possíveis para auxiliar as cidades a se tornarem mais adaptadas as características climáticas locais, garantindo melhores condições de ocupação espacial. Destaca-se ainda a influência do urbanismo e da ação das políticas publicas, reconhecendo que a criatividade e a mudança são importantes fatores para a promoção do bemestar da população e da sua qualidade de vida.

\section{METODOLOGIA}

\subsection{Características Climáticas de Cuiabá}

Cuiabá é conhecida popularmente pela elevada temperatura do ar e consequente sensação de calor. Campelo Jr. et al. (1991), afirma que na cidade a temperatura observada no período de primavera-verão, varia entre $30^{\circ} \mathrm{C}$ e $36^{\circ} \mathrm{C}$. O inverno tem uma particularidade, apresentando em média 17 dias por ano com temperaturas inferiores a $20^{\circ} \mathrm{C}$ e apenas 8 dias por ano com temperatura média inferior a $18^{\circ} \mathrm{C}$.

Segundo dados do INMET (2003) a cidade possui uma pequena amplitude térmica, exceto em fenômenos de friagem, apresentando uma temperatura média anual de $26,8^{\circ} \mathrm{C}$, com média das máximas de $42^{\circ} \mathrm{C}$ e médias das mínimas de $15^{\circ} \mathrm{C}$ e insolação total média de 2.179 horas. A direção predominante dos ventos é $\mathrm{N}$ e $\mathrm{NO}$ durante boa parte do ano e $\mathrm{S}$ no período de inverno. "É importante ressaltar que, apesar da reduzida velocidade do vento predominante, ocorrem rajadas (picos de velocidade de curta duração)" (CAMPELO Jr. et al., 1991).

\section{2. Área de estudo}

O estudo foi realizado no centro histórico de Cuiabá, foi traçado uma trajetória que percorria trechos das ruas Eng. Ricardo Franco, Eng. Galdino Pimentel, Rua dos Bandeirantes, Voluntários da Pátria, Campo Grande e Cândido Mariano. Determinando 22 pontos de coleta das variáveis ambientais conforme segue no mapa abaixo (Figura 1). 


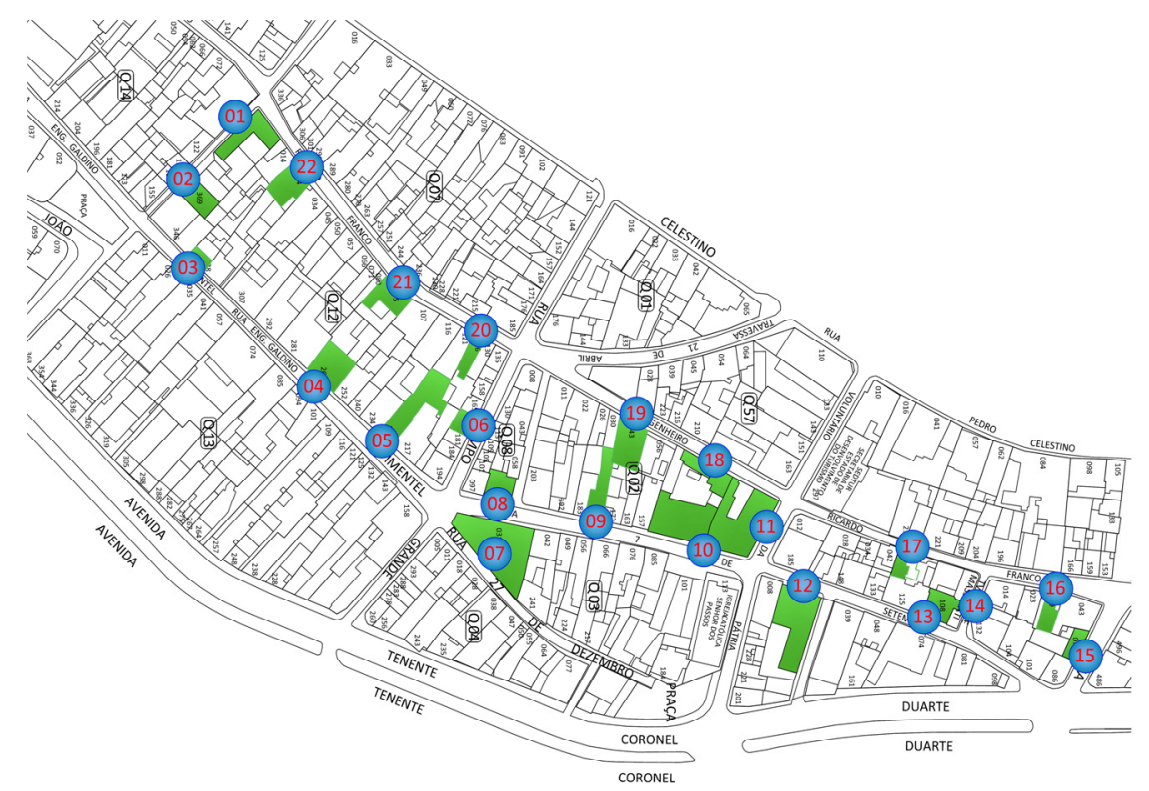

Figura 01 - Mapa contendo os 22 pontos do transecto realizado no centro histórico de Cuiabá-MT Fonte: Próprio Autor

\subsection{Coleta de dados micrometeorológicos}

O levantamento microclimático foi realizado no dia 06 de março de 2012, utilizou-se o método do transecto móvel, onde fez se a coleta de dados micrometeorológicos percorrendo um caminho, determinou-se 21 pontos onde se aferiu a temperatura do ar, umidade relativa e velocidade do vento. O percurso foi realizado a pé e tinha duração de aproximadamente 30 minutos, em três horários distintos às $8 \mathrm{~h}, 13 \mathrm{~h}$ e $18 \mathrm{~h}$, com o intuito de se verificar o comportamento térmico ao longo do dia. Segundo Maitelli (1994) o método do transecto móvel permite avaliar melhor o comportamento térmico e higrométrico em um espaço maior dentro do contexto urbano.

Para a coleta de dados no transecto móvel foi utilizado o Termo-higro-anemômetro digital portátil, Modelo THAR - $185 \mathrm{H}$ da marca Instrutherm. Construiu-se um abrigo para proteger o Termo-higro-anemômetro da radiação solar direta e precipitação durante a coleta de dados no transecto móvel.

\section{RESULTADOS E DISCUSSÕES}

O Centro histórico de Cuiabá, Figura 2, ainda apresenta características que remetem a época de sua colonização: as casas sem afastamentos frontal e lateral, as ruas estreitas, a presença constante da vegetação e da água nos pátios internos, os pavimentos em pedra, a presença de grandes e numerosas aberturas nas edificações, são alguns dos traços desta herança da adaptação dos colonizadores as adversidades locais. Segundo Holanda (1985), os portugueses realizavam experiências sucessivas, que não necessariamente tinham ligação umas às outras, trabalhando o traçado de maneira provisória sem uma continuidade. $O$ autor fala ainda sobre as vilas que por várias vezes eram fundadas e depois se alterava uma, duas ou mais vezes seu sítio. 


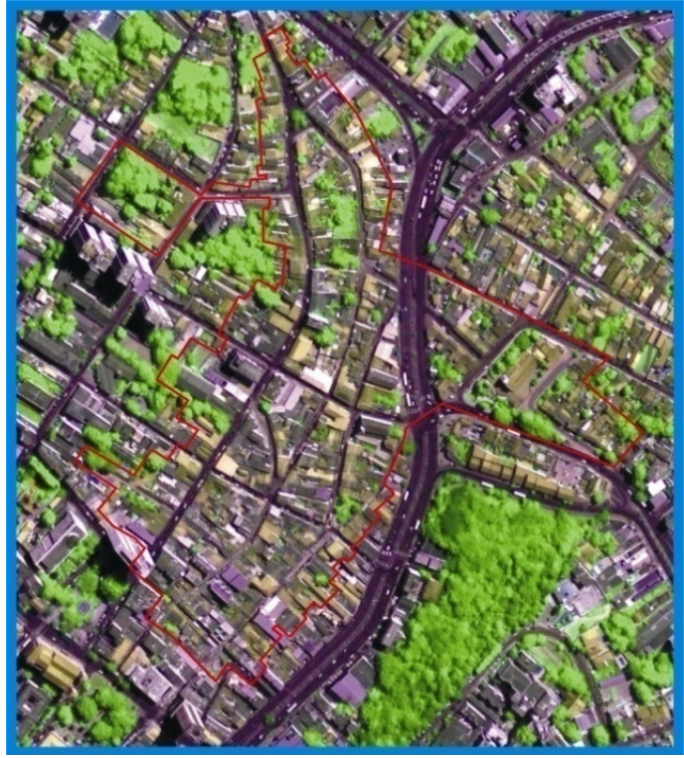

(a)

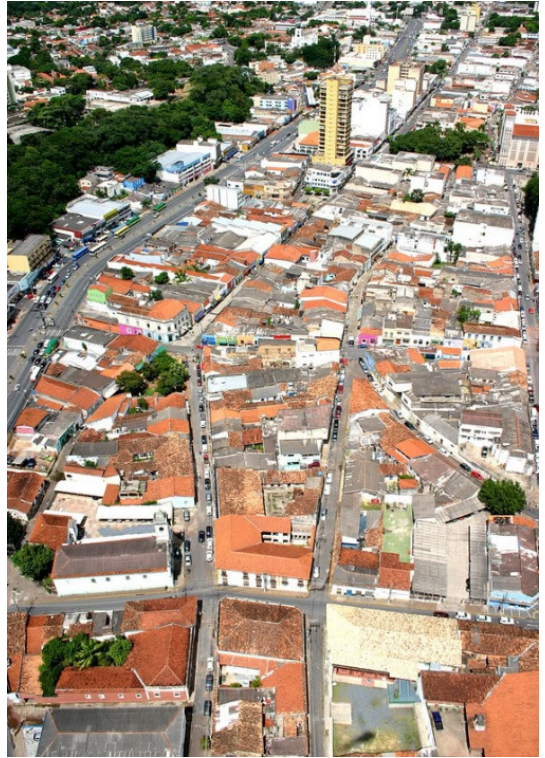

(b)

Figura 02 - (a) Imagem do satélite Ikonos da área do Centro Histórico e entorno

Fonte: Sanches 2005

(b) Imagem área do Centro Histórico

Fonte: www. skyscrapercity.com

O traçado continuo e fechado das edificações, resultado da ausência de afastamentos entre os lotes, e a direção paralela das ruas em relação aos ventos predominantes permite que aquelas funcionem como verdadeiros canais de vento. Givoni (1989) lembra que há melhor ventilação nas ruas quando elas são paralelas ou inclinadas em até certo ponto na direção dos ventos predominantes durante o período da tarde, quando a temperatura do ar atinge seu máximo.

No entanto a velocidade do vento em Cuiabá geralmente é insuficiente para caracterizar uma situação de conforto, por causa da configuração geográfica de depressão da zona urbana, apresentando apenas algumas rajadas de maior velocidade. Em estudo realizado em praças, Oliveira (2011) afirma que os valores mais freqüentes da velocidade do vento são de $0,0 \mathrm{~m} / \mathrm{s}$, correspondendo a $27 \%$ dos dados, tanto para os períodos seco quanto para o chuvoso, e $85 \%$ ficam concentrados aproximadamente em velocidades de até $1,0 \mathrm{~m} / \mathrm{s}$. As maiores velocidades médias são observadas por volta das $14: 00 \mathrm{~h}$, com valores de até $2.6 \mathrm{~m} / \mathrm{s}$ no início da estação chuvosa (MAITELLI, 1994). Em regiões continentais, como é o caso de Cuiabá, as calmarias frequentes intensificam o stress térmico causado pela combinação de altas temperaturas e umidade durante a estação chuvosa.

No levantamento contendo as características dos ventos no centro histórico notam-se algumas propriedades já encontradas na literatura. No gráfico de velocidade do vento observa-se que $32 \%$ das velocidades do vento foram igual a $0 \mathrm{~m} / \mathrm{s}, 53 \%$ com variação de 0,1 a $0,9 \mathrm{~m} / \mathrm{s}$ e apenas $15 \%$ acima de $1 \mathrm{~m} / \mathrm{s}$. Apenas os pontos $6,7,10,11,12$ e 17 obtiveram velocidades do vento maiores que $1 \mathrm{~m} / \mathrm{s}$ a característica em comum entre os pontos é a altura das edificações todas de 2 pavimentos e a pouca largura da rua. (Figura 3) 


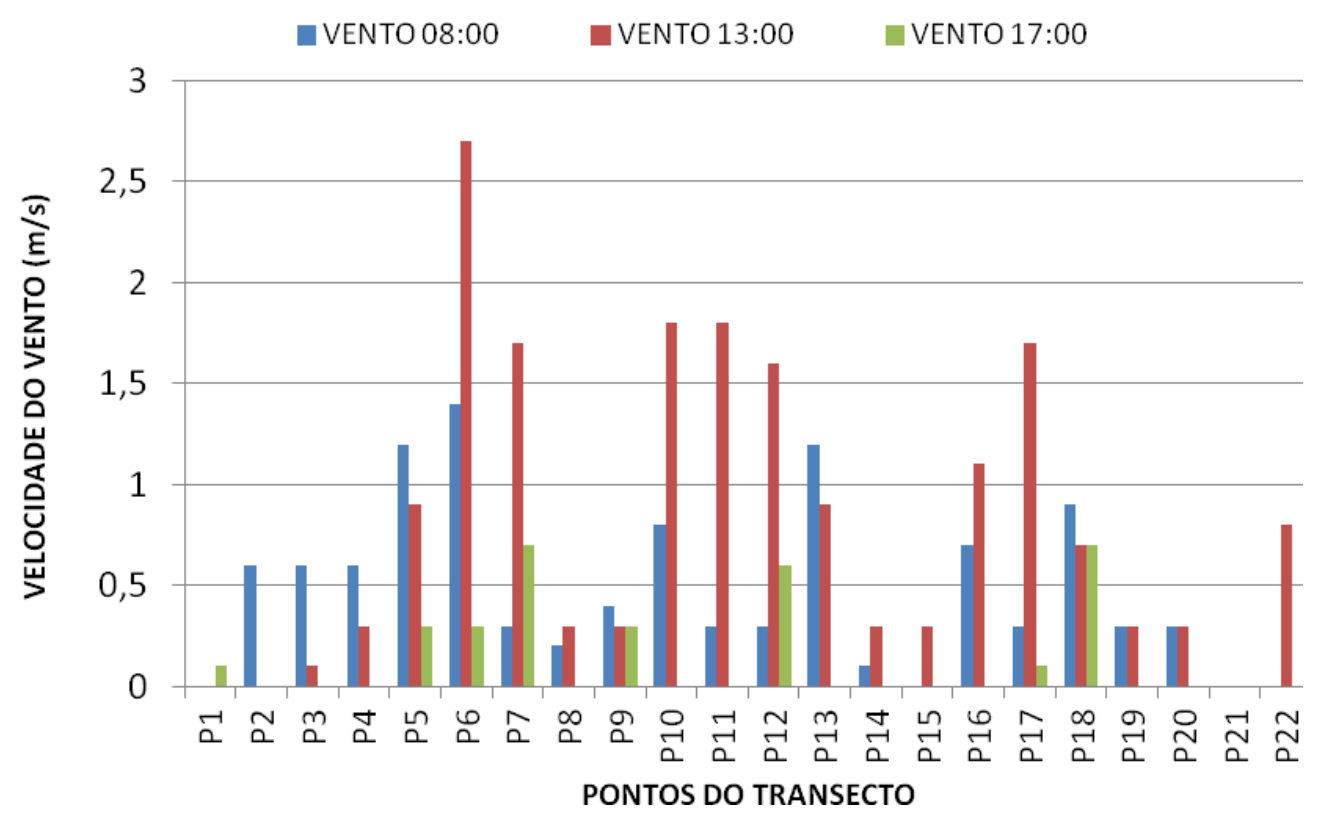

Figura 03 - Gráfico de velocidade do vento

Fonte: Próprio Autor

A estreita largura e a orientação predominantemente Norte-Sul das ruas do centro histórico de Cuiabá também propiciam que as edificações funcionem como uma barreira para a incidência solar direta. O resultado final se altera na medida em que são encontradas diferentes alturas nas edificações, o que caracteriza diferentes períodos de insolação direta para cada porção das vias. No entanto, mesmo quando as edificações não apresentam grandes alturas, as estreitas larguras observadas nas ruas permitem um elevado efeito de canyon, fazendo com que as horas de incidência solar direta sejam significativamente inferiores às encontradas em outras localidades da cidade, caracterizadas por amplas vias de tráfego de veículos.

A Figura 04 apresenta as temperaturas do ar registrado em três horários distintos, notase a maior temperatura no horário das $13 \mathrm{~h}$ variando de $36^{\circ} \mathrm{C}$ á $38,7^{\circ} \mathrm{C}$ e as menores temperaturas no horário das $8 \mathrm{~h}$ variando de $28,5^{\circ} \mathrm{C}$ á $33,5^{\circ} \mathrm{C}$. Os pontos onde se encontravam as menores temperaturas estavam localizados em regiões onde o traçado urbano favorecia o sombreamento, ou seja ruas estreitas e edificações de mais de um pavimento, como por exemplo podemos citas o ponto 9 e 13.

Johansson (2006) investigou a influência da geometria urbana no conforto térmico ao ar livre, comparando um canyon urbano profundo e estreito, fruto de um traçado antigo, e um canyon urbano raso e largo, localizado em um bairro novo em Fez, Marrocos. As medições durante o verão quente apresentam menores temperaturas no canyon profundo quando comparado ao canyon raso. No verão, a diferença máxima era, em média, $6^{\circ} \mathrm{C}$ e $10^{\circ} \mathrm{C}$, durante os dias mais quentes. 


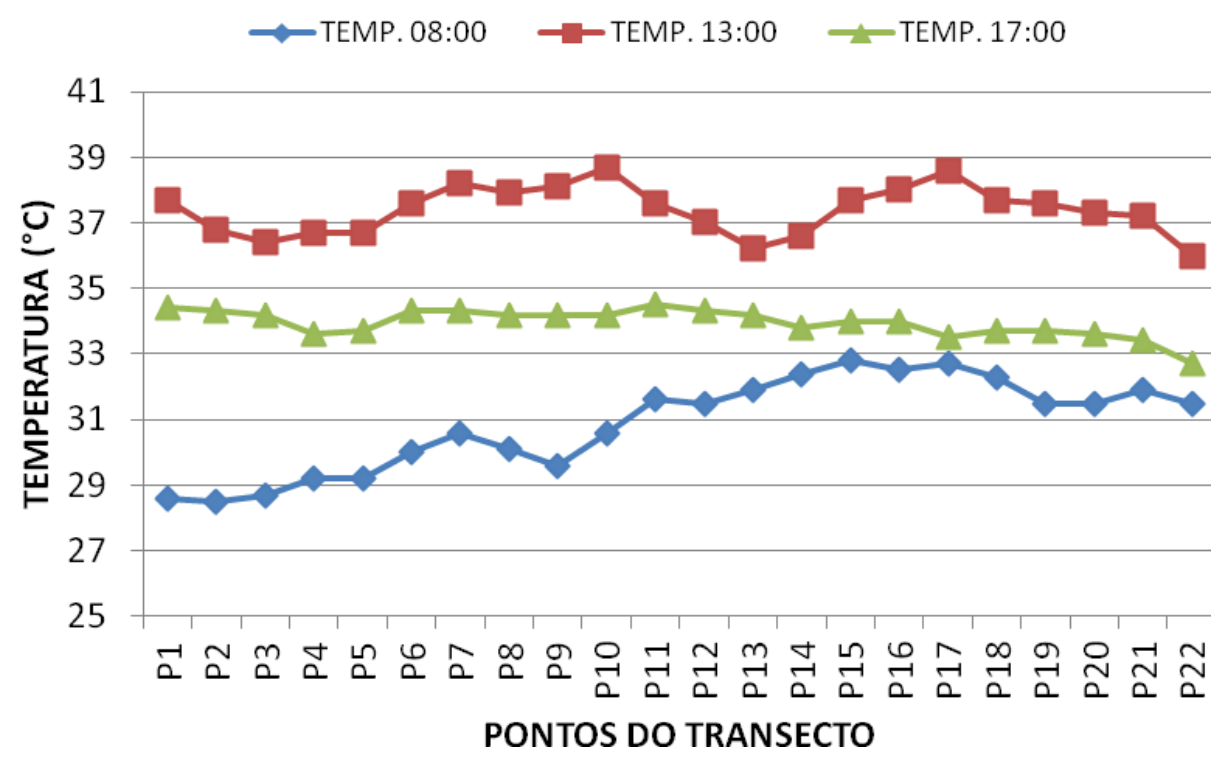

Figura 04 - Transecto da temperatura do ar na região central em Cuiabá

Fonte: Próprio Autor

Em estudo realizado por Sanches (2005), no qual foi desenvolvido um levantamento da temperatura e umidade relativa do ar no centro histórico de Cuiabá, de forma a determinar os efeitos do traçado urbano como fator de amenização climática do entorno imediato, observa-se na estação seca a maior sensação de desconforto devido às altas temperaturas do ar e baixas umidades. No gráfico apresentado observa-se que no horário mais critico na pior situação climática a menor temperatura é encontrada em uma viela, característica do centro histórico, como verificado na figura 05 , o que demonstra que o fator canyon urbano está intimamente ligado ao comportamento térmico local.

Este fenômeno de sombreamento das vias contribui para a diminuição da carga térmica absorvida pelos pavimentos e fechamentos das edificações, o que possibilita uma redução nas temperaturas do ar interno e externo. Também o uso de materiais mais reflexivos nos fechamentos permite uma menor absorção da carga térmica incidida pelo sol, contribuindo mais uma vez para a criação de um ambiente mais confortável para o pedestre. É o caso, por exemplo, da pedra utilizada de forma predominante como pavimento nas ruas do centro, ela apresenta maior resistência a absorção da radiação incidente que os pavimentos asfálticos normalmente utilizados nas vias da cidade. 

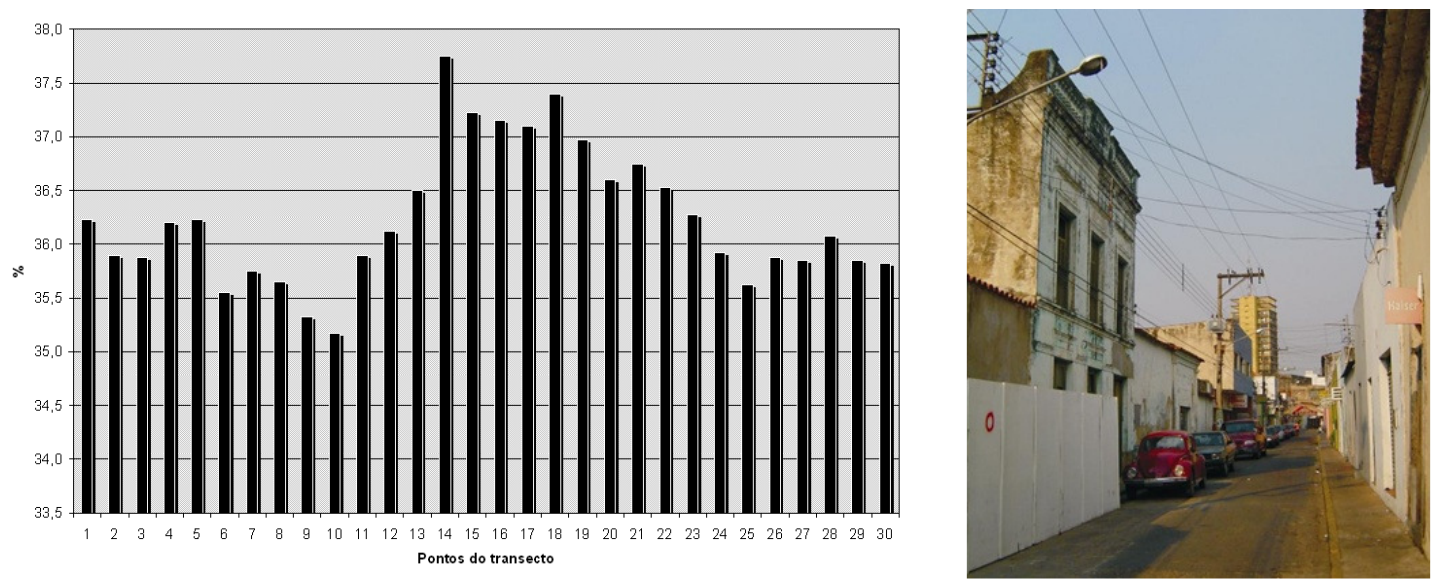

Figura 05 - Média das temperaturas do ar média nos pontos estudados, na estação seca, 14h., foto do ponto 10 (menor temperatura do ar)

Fonte: SANCHES (2005)

Em estudo recente realizado em Atenas na Grécia Santamouris et. al (2012) realiza a aplicação de $4500 \mathrm{~m}^{2}$ de pavimentos reflexivos em um parque urbano com o objetivo de melhorar as condições de conforto e reduzir a intensidade da ilha de calor. Para avaliar o impacto térmico de arrefecimento do material foram feitas análises das condições climáticas antes e depois da aplicação dos revestimentos, ao final do esperimento estimou-se que a utilização de pavimentos frescos contribui para a redução da temperatura de pico durante um dia típico de verão em até $1,9^{\circ} \mathrm{C}$. Ao mesmo tempo, a temperatura da superfície no parque reduziu $12^{\circ} \mathrm{C}$, permitindo que as condições de conforto fossem consideravelmente melhoradas.

Outra característica observada nas edificações vernaculares cuiabanas é a presença dos quintais. Estes ambientes formavam verdadeiros jardins na região central da casa para onde a maioria dos cômodos se voltavam, permeados por uma estreita varanda. Estes jardins internos alem de contribuir para a criação de um microclima de menores temperaturas e maiores umidades do ar no interior das edificações também contribuíam para o ambiente térmico urbano, pois permitiam a criação de parcelas de vegetação no centro dos quarteirões, que pela permeabilidade possibilitada pelos grandes vãos das janelas e portas, levavam este microclima para as ruas. Limor Shanshua-Bar et. al. (2010) revelou que em Atenas o efeito de atenuação que a vegetação pode proporcionar nas temperaturas do ar observadas nas ruas pode atingir $5^{\circ} \mathrm{C}$ ao meio-dia, tendo um arrefecimento médio diário de $3^{\circ} \mathrm{C}$.

No centro histórico ainda existem algumas edificações com essa características, como é o caso da residência que abriga o IPHAN (Instituto do Patrimônio Histórico e Artístico Nacional) retratada na Figura 06, o jardim interno é um elemento muito presente na arquitetura mourisca, que por sua vez foi grande influência para a arquitetura portuguesa. No entanto o uso da vegetação no centro histórico não se resume aos quintais, pode ainda ser observada em praças e canteiros centrais com espécies frutíferas, tendo a presença sempre constante das mangueiras, sendo este um recurso utilizado empiricamente nas moradias desde o inicio do século passado, que serviam também como fonte de alimento. 


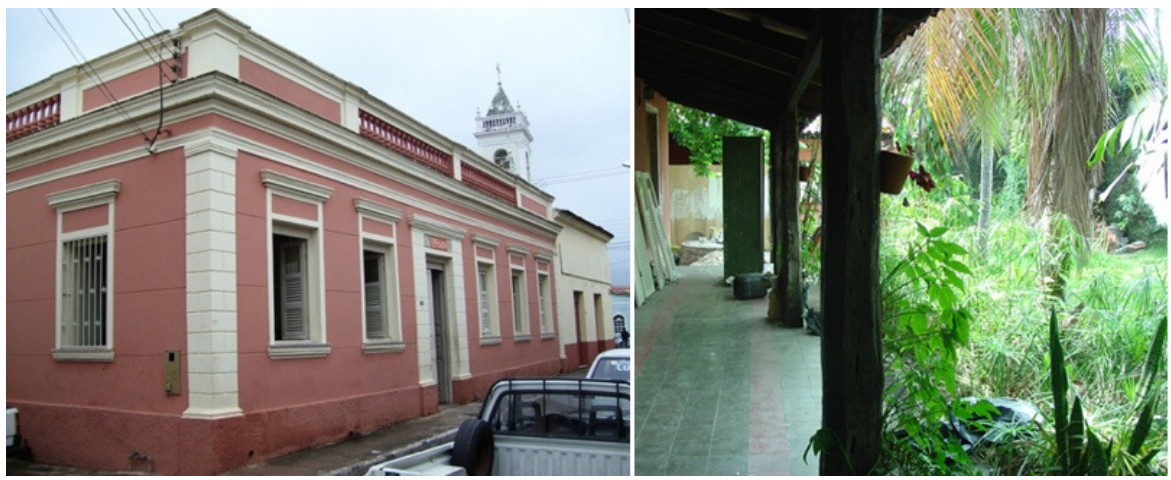

Figura 06 - Residência sede do IPHAN

Fonte: Acervo Próprio

O uso da água como elemento urbano, outra característica marcante da arquitetura cuiabana, ainda é notado tanto em algumas praças localizadas no centro quanto nos jardins internos localizados na região central dos quarteirões (Figura 07). Duarte (2000) afirma que os reflexos na água, combinados com jogos de luz e sombra, eram elementos centrais na arquitetura mourisca, que juntamente com o uso de vegetação e do sombreamento permitem a criação de espaços ao ar livre com um microclima diferenciado em relação à aridez local, aumentando a umidade do ar, reduzindo ganhos térmicos pela radiação solar e diminuindo a temperatura do ar. Robitu et al. (2006) afirma que as árvores e os reservatórios de água devem ser considerados como meios reais para a melhoria das condições microclimáticas no espaço exterior. 0 resfriamento evaporativo é indiscutivelmente uma das formas mais eficientes de refrigeração passiva para edifícios e espaços urbanos em regiões quentes (GIVONI, 1991).

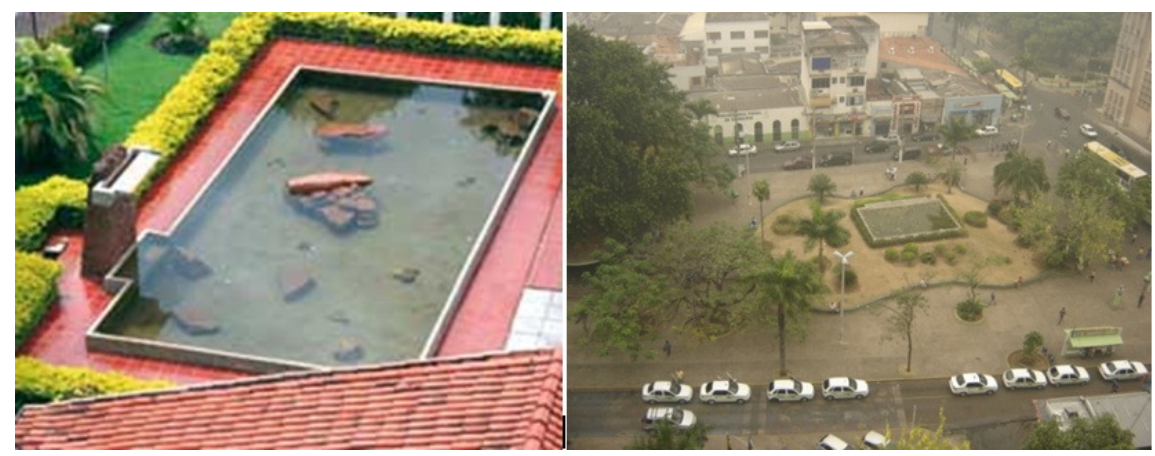

Figura 07 - Jardim da antiga casa do governador e Praça Alencastro

Fonte: www. skyscrapercity.com

As praças (Figura 08) são ambientes urbanos muito presentes no traçado do centro antigo. Muitas praças na área central da cidade já foram recuperadas e estão sendo mantidas pela iniciativa privada, geralmente por comerciantes próximos a esses locais, em troca de uso do espaço para publicidade. No Brasil a presença de praças e largos vem de longa data, remontando aos primeiros séculos da colonização e ocupando a posição de valorizadores do espaço com função organizacional. As praças no Brasil colônia estavam associadas aos adros das igrejas, servindo para reunião de pessoas e diversas atividades, não só religiosas como também as de recreio, mercado, políticas e militares. 
Oliveira (2011), em estudo desenvolvido em duas praças localizadas no centro de Cuiabá observou que regiões mais arborizadas e com sombra densa apresentaram menores valores de temperatura superficial, quando comparados com aquelas não arborizadas. Isto confirma que a vegetação contribuiu significativamente para o não aquecimento das superfícies do solo das praças.

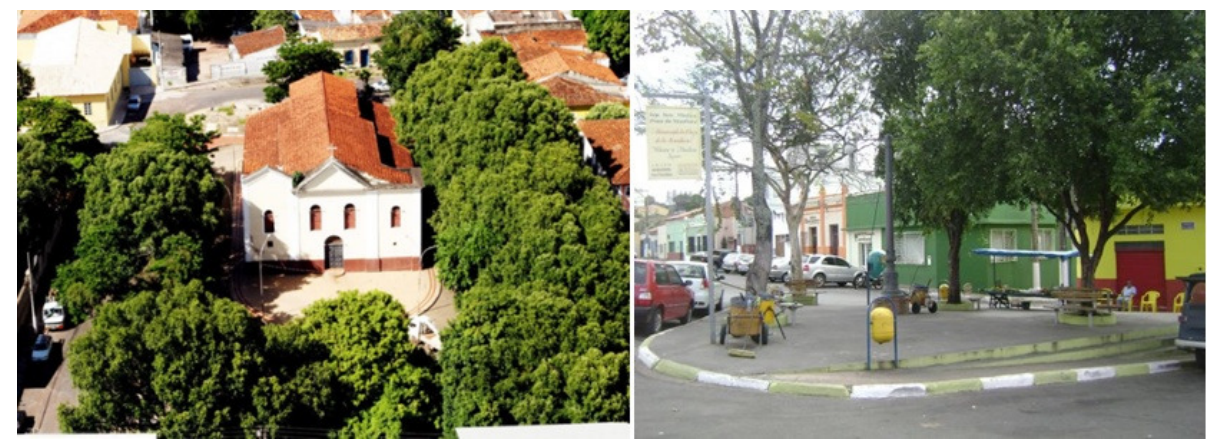

Figura 08 - Praça da Boa Morte e Praça da Mandioca

Fonte: www. skyscrapercity.com

\subsection{Diretrizes}

\subsubsection{Vegetação urbana}

Sob essas condições climáticas, presentes em muitas cidades brasileiras de clima tropical continental, para se chegar a um microclima desejado Givoni (1994) coloca o sombreamento como pré-requisito para os espaços externos antes de qualquer outra medida, porque a proteção à radiação solar tem um grande efeito psicológico na redução do stress térmico. Se as superfícies sombreadas também forem úmidas, natural ou artificialmente, a sua temperatura cai para a temperatura de bulbo úmido que, na estação seca, pode ser significativamente menor do que a temperatura do ar. $\mathrm{O}$ autor complementa dizendo que o ideal seria criar caminhos para que o pedestre pudesse percorrer toda a cidade sob um teto verde, protegido da intensa radiação solar, bons exemplos podem ser notados em Mendonza na Argentina e nos Jardim do Generalife na Espanha (Figura 09).

A arborização das vias é um recurso prático e econômico que pode ser incentivado pelo uso de políticas abatimento ou desconto na taxa de IPTU ou mesmo pela instituição de incentivos quanto a certificação de qualidade da edificação. No entanto é primordial que seja feita uma orientação quanto as espécies a serem cultivadas e as formas de plantio. Tsiros (2010) realizou medições de temperatura do ar sob o dossel de árvores em ruas do subúrbio na cidade de Atenas na Grécia. $O$ efeito do arrefecimento médio as $14 \mathrm{~h}$ foi de $0,5^{\circ} \mathrm{C}$ a $1,6^{\circ} \mathrm{C}$ e as $17 \mathrm{~h}$ de $0,4^{\circ} \mathrm{C}$ a $2,2^{\circ} \mathrm{C}$; ressaltando o potencial arrefecimento passivo da sombra das árvores. 

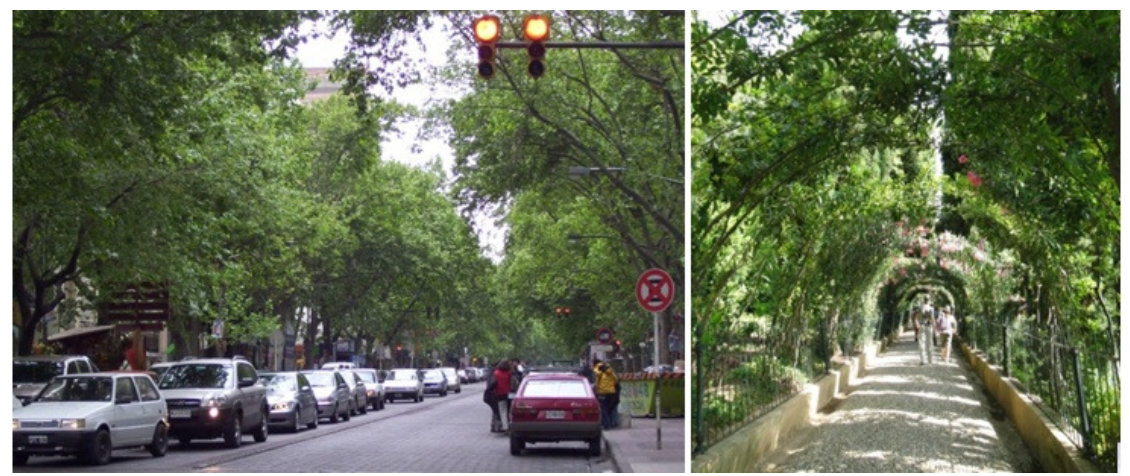

Figura 09 - Rua em Mendoza Argentina e Passarela nos Jardins do Generalife

Fonte: www. skyscrapercity.com

A arborização urbana além de melhorar as condições climáticas exteriores protege a edificação da radiação solar direta diminuindo assim os ganhos térmicos e conseqüentemente o gasto com refrigeração. Em estudos realizados em Atenas, Tsiros (2010) comprova, usando pressupostos simplificados, que o uso de cobertura de árvores nas ruas pode reduzir o consumo de hora de uso de ar condicionado no verão durante o dia de $2,6 \%$ a 8,6\% e nos horários de pico de $2,9 \%$ a $9,7 \%$.

Além dos espaços das ruas e quintais a vegetação pode ocupar também as coberturas das edificações. Segundo Levallius (2005), as coberturas com vegetação oferecem a vantagem de utilizar a superfície livre das coberturas nas edificações, mitigando ao mesmo tempo alguns problemas urbanos. Segundo pesquisa realizada na Alemanha, comprovou-se que para temperaturas do ar externo com valor de $30^{\circ} \mathrm{C}$, a temperatura no substrato da cobertura verde não ficou acima dos $25^{\circ} \mathrm{C}$. A atenuação térmica proporcionada no verão pelas coberturas verdes é ainda mais evidente do que o efeito da isolação térmica no inverno (MINKE, 2003).

\subsubsection{Canyons urbanos}

Emmanuel (1993), em estudo para climas equatoriais, afirma que a geometria urbana é um dos fatores mais importantes da mudança climática, pelo menos em micro-escala. $O$ autor propõe a manipulação da geometria para explorar o potencial de sombreamento das massas edificadas, visando a redução da radiação solar nos ambientes externos durante o dia.

Para isso sugere-se a incorporação de diretrizes, nas leis de uso e ocupação do solo presentes no plano diretor, que determinem o gabarito das edificações baseado na largura das vias, permitindo um maior controle sobre os efeitos de sombreamento proporcionados nos canyons urbanos. As diretrizes para cidades de clima equatorial devem buscar por maiores profundidades e menores larguras de canyons enquanto em cidades de clima mais temperado deve-se optar por canyons mais largos e rasos.

\subsubsection{Propriedade térmica dos revestimentos}

A cidade modifica o clima através das alterações em sua superfície, produzindo aumento de energia térmica, modificações no fluxo de vento, diminuição da umidade relativa, e diminuição da infiltração da água das chuvas, em função do aumento da superfície impermeável formada pela pavimentação e área construída. Isso ocorre porque a substituição dos materiais naturais pelos materiais urbanos provoca mudanças nos processos de absorção, transmissão e reflexão, e nas características da atmosfera local (DUARTE, 2000). 
Em cidades de clima quente devem-se utilizar revestimentos mais reflexivos, ou seja, que quando submetidos a incidência solar, absorvam uma pequena parcela da radiação, provocando assim menores alterações na sua temperatura inicial. Esses materiais permitem que uma menor parcela da radiação seja emitida em forma de calor tanto para o ambiente externo quanto para o interno.

Já em localidades de clima frio recomenda-se a utilização de revestimentos absorventes. De forma inversa a descrita anteriormente, esses materiais permitem que uma maior parcela da radiação incidente seja absorvida e reemitida na forma de calor para o seu entorno.

\subsubsection{Uso da água como elemento integrante da paisagem urbana}

Altas temperaturas são verificadas em áreas de crescimento vertical intenso, elevada densidade demográfica e pouca quantidade de vegetação, principalmente nos setores industriais e residenciais. Já as regiões com maior concentração de espaços livres, com vegetação ou nas proximidades de reservatórios d'água, as temperaturas sofrem declínios acentuados, porque a maior quantidade de vegetação implica em mudança no balanço de energia (LOMBARDO, 1985).

De acordo com Dominguez (1992), apesar da radiação solar absorvida por uma lâmina d'água ser considerável, com valores de até $80 \%$, esta absorção não origina uma elevação de temperatura da água, devido à evaporação e à inércia térmica da massa de água.

Podem-se utilizar os espelhos d'água:

a) Sob a forma de lâminas horizontais situadas em zonas expostas ao sol adjacentes a zonas de passagem ou permanência, o que combina duas vantagens, baixa temperatura superficial e baixa refletividade. A refletividade é função do ângulo de incidência da radiação solar, sendo menor (da ordem de 3\%) quando o sol está alto, ou seja, nos momentos mais desfavoráveis;

b) Sob a forma de cascata e paredes de água internas ou próximas às zonas ocupadas.

De acordo com Dominguez (1992), o uso de lâminas d'água pode ser extraordinariamente efetivo e alcançar reduções de temperatura da ordem de $12{ }^{\circ} \mathrm{C}$ para coberturas de cor clara e de 20 ㄷ $\mathrm{C}$ para coberturas de cor média em comparação com as mesmas coberturas secas. Quanto ao uso de espelhos d'água, de acordo com Guerra Macho et al. (1994), o efeito sobre o ocupante é, de certa maneira, proporcional a como a pessoa vê a lâmina d'água, ou seja, depende do fator de forma ocupante/superfície da água. Assim é importante facilitar a circulação dos visitantes pelas zonas próximas à lâmina d'água que, ao sol, mantém uma temperatura inferior a de um pavimento convencional. Esse processo é melhorado com a instalação de aspersores que aumentam a superfície de troca de calor água/ar e, portanto, a taxa de evaporação.

Recomenda-se então, principalmente em cidades de clima seco, a manutenção dos recursos d'água presentes no perímetro urbano de forma a permitir que esses efeitos possam ser percebidos pelos ocupantes. Devendo-se juntamente instituir políticas de limpeza e preservação desses cursos d'água, (Figura 10). 

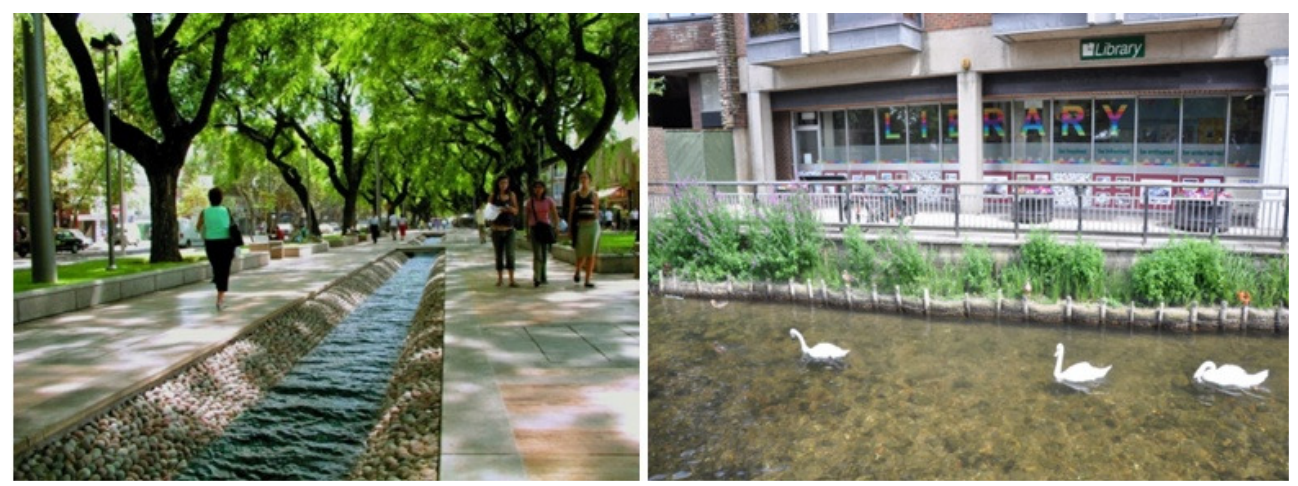

Figura 10 - Canal em Mendoza Argentina e Rio em Salisbury Inglaterra

Fonte: www. skyscrapercity.com

\section{CONCLUSÕES}

A concepção do espaço citadino, distribuição de vias, ocupação do solo, locação de equipamentos de lazer entre outros são parte da decisão dos planejadores urbanos, que muitas vezes não atentam aos costumes, tradições e comportamentos locais. Assim trazendo da academia uma idéia engessada a respeito de como conceber o espaço urbano, podendo existir nessa atitude dois contratempos, um projeto inexeqüível devido ao nível de teorização ou um projeto deslocado da realidade e interesses locais.

O modo empírico como a cidade é concebida, muitas vezes traz lições que podem e devem ser aplicada ao planejamento urbano, o centro histórico de Cuiabá, projetado baseado na experiência dos colonizadores, apresenta características da arquitetura bioclimática. Um planejamento urbano sustentável é fruto de um trabalho conjunto que envolve antes de tudo respeito pelo clima, cultura, economia e história local.

As diretrizes de urbanismo precisam sair do papel através do esforço do planejador para que a população tenha um ambiente coletivo melhor e mais bem utilizado, as pessoas precisam sentir-se familiarizadas e integrantes dos espaços criados, sentindo se motivadas a apropriar-se dele.

\section{AGRADECIMENTO}

À Eletrobras e CAPES pelo apoio financeiro na realização desta pesquisa.

\section{REFERÊNCIAS BIBLIOGRAFICAS}

CAMPELO JUNIOR, J. H.; PRIANTE FILHO, N.; CASEIRO, F. T. Caracterização macroclimática de Cuiabá. In: III ENCONTRO NACIONAL DE ESTUDOS SOBRE O MEIO AMBIENTE, 1, 1991, Londrina. Anais. Londrina/ PR, 1991. p.542-552.

DOMINGUEZ A. SERVANDO ET AL. Control Climático en Espacios Abiertos. In: El Proyecto EXPO'92, 1992, Sevilha. CIEMAT. Sevilha/ Espanha, 1992.

DUARTE, D. H. S. Padrões de ocupação do solo e microclimas urbanos na região de clima tropical continental. 2000. 278f. Tese (Doutorado em Arquitetura) - Faculdade de Arquitetura e Urbanismo da Universidade de São Paulo. São Paulo/SP, 2000.

FREIRE, J. L. Por Uma Poética Popular da Arquitetura. 1988. Dissertação (Mestrado em Artes) Escola de Comunicação e Artes/ ECA, Universidade de São Paulo. São Paulo/ SP, 1988. 
FREIRE, J. L. Cuiabá Nosso Bem Coletivo. 1 ed. Cuiabá/ MT: Ed. Entelinhas, 1992, $137 f$.

GIVONI, B. Urban Design in Different Climates. Geneva: WMO Technical Document, 1989. n.346.

GIVONI, B. Impact of planted areas on urban environmental quality: a review. Atmospheric Environment, Oxford, v.25B, n.3, p.289-199. (1991).

GIVONI, B. Passive and Low Energy Cooling of Buildings. New York: John Wiley \& Sons, Estados Unidos, 272f, Julho, 1994.

GUERRA MACHO, J. J. et al. Control Climático em Espacios Abiertos. In: Evaluación del Proyecto EXPO'92, 1992, Sevilha. CIEMAT. Sevilha/ Espanha, 1992.

HOLANDA, S. B. Raízes do Brasil. Rio de Janeiro/ RJ. Ed. José Olympio, 1985, 161p.

INMET no Distrito Federal. In: INSTITUTO NACIONAL DE METEOROLOGIA. Climatologia. 2003. Disponível em: http://www.inmet.gov.br/climatologia. Acesso em: 20 jun. 2009.

JOHANSSON E. Influence of urban geometry on outdoor thermal comfort in a hot dry climate: A study in Fez Morocco. Building and Environment, Estados Unidos, v 41, p 1326-1338, 2006.

LEVALLIUS, J. Green roofs on municipal buildings in Lund - Modeling potential environmental benefits. Physical Geography and Ecosystems Analysis, Geobiosphere Science Centre. Lund University, 2005.

LOMBARDO, M. Ilha de calor nas metrópoles. São Paulo: Hucitec. 1985. $244 f$.

MAITELLI, G. T. Uma Abordagem Tridimensional de Clima Urbano em Área Tropical Continental: o exemplo de Cuiabá - MT. 1994. 220f. Tese (Doutorado em Geografia) - Faculdade de Filosofia, Letras e Ciências Humanas, Universidade de São Paulo, São Paulo/ SP, 1994.

MINKE, G. Techos verdes. Planificación, ejecución, consejos práticos. Montevideo: Fin de Siglo. 2003.

OLIVEIRA, A. S. Influência da vegetação arbórea no microclima e uso de praças públicas. 2011. 149f - Tese (Doutorado em Física Ambiental) - Universidade Federal de Mato Grosso, Cuiabá/ MT, 2011.

PEARLMUTTER D., BITAN A. BERLINER, P. Microclimatic analyses of compact urban canyons in an arid zone. Atmospheric Environment, Oxford, v.33, n²4-25, p.4143-4150, 1999.

POLIÃO, M. V. Da arquitetura. São Paulo. Hucitec, Annablume. Tradução de: Viitruvii de Arquitetura Libri Decem.Reis Filho, N. G. (1968) Contribuição ao Estudo da Evolução Urbana do Brasil. São Paulo: Editora Pioneira / EDUSP. 1999. 
ROBITU M., MUSY M., INARD C.,GROLEAU D. Modeling the influence of vegetation and water pond on urban microclimate. Solar Energy, Estados Unidos, v.80, 2006.

ROMERO, M. A. Arquitetura Bioclimática do Espaço Público. 1. ed. Brasília: Editora Universidade de Brasília. 2001. $225 \mathrm{f}$.

SHASHUA-BAR L.,TSIROS I. X., HOFFMAN M. E. A modeling study for evaluating passive cooling scenarios in urban streets with trees. Case study: Athens, Greece. Building and Environment, Estados Unidos, v.45, p 2798-2807, 2010.

SANCHES, J. C. M. O estudo de microclimas como ferramenta para o planejamento urbano. 2005. Dissertação (Mestrado) - Programa de Pós-Graduação em Geografia, Universidade Federal de Mato Grosso, Cuiabá/ MT, 2005.

SANTAMOURIS M., GAITANI N., SPANOU A., SALIARI M., GIANNOPOULOU K.,VASILAKOPOULOU K., KARDOMATEAS T. Using cool paving materials to improve microclimate of urban areas e Design realization and results of the flU. Us project. Building and Environment, Estados Unidos, v.53, p 128-136, 2012.

TSIROS I. X. Assessment and energy implications of street air temperature cooling by shade trees in Athens (Greece) under extremely hot weather conditions. Renewable Energy. Estados Unidos, v.30, p 1-4, 2010.

Identificação dos Autores:

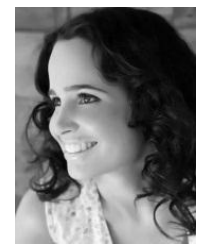

Fernanda Miguel Franco

Graduação em Arquitetura e Urbanismo pela Universidade Federal de Mato Grosso/ UFMT;

Professora Efetiva do Instituto Federal de Mato Grosso/ IFMT;

Doutoranda pelo Programa de Pós Graduação em Física Ambiental/ PPGFA/ UFMT, Linha de Pesquisa: Análise

Microclimáticas em Sistemas Urbanos, E-mail: fermifran@hotmail.com

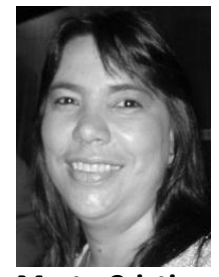

Marta Cristina de Jesus Albuquerque Nogueira

Graduação em Engenharia Civil pela Universidade Federal de Mato Grosso/ UFMT;

Professor Efetiva do Departamento de Arquitetura e Urbanismo/ UFMT;

Professora do Programa de Pós Graduação em Física Ambiental/ PPGFA/ UFMT, Linha de Pesquisa: Análise

Microclimáticas em Sistemas Urbanos, E-mail: mcjanp@gmail.com 


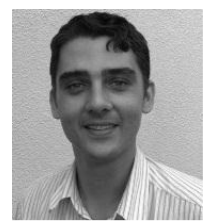

\section{Osvaldo Borges Pinto Júnior}

Graduação em Ciências Biológicas pela Universidade Estadual de Mato Grosso/ UNEMAT;

Professor Efetivo da Universidade de Cuiabá/ UNIC;

Professor do Programa de Pós Graduação em Física Ambiental/ PPGFA/ UFMT, Linha de Pesquisa: Análise Microclimática em Sistemas Urbanos, E-mail: osvaldo.borges@gmail.com

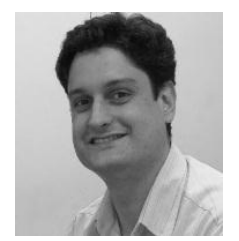

\section{Marcelo Sacardi Biudes}

Graduação em Licenciatura Plena em Física pela Universidade Federal de Mato Grosso/ UFMT; Professor Efetivo do Instituto de Física/ UFMT;

Professor do Programa de Pós Graduação em Física Ambiental/ PPGFA/ UFMT, Linha de Pesquisa: Análise Microclimática em Sistemas Urbanos, E-mail: marcelo.biudes@gmail.com

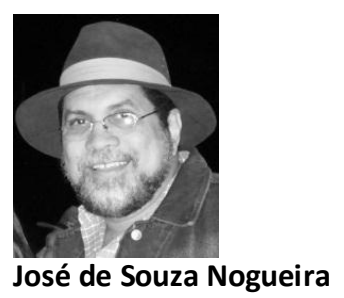

Graduação em Licenciatura Plena em Física pela Universidade Federal de Mato Grosso/ UFMT;

Professor Efetivo do Instituto de Física/ UFMT;

Professor do Programa de Pós-Graduação em Física Ambiental e Coordenador do Programa de Pós-Graduação em Física Ambiental em nível de Mestrado e Doutorado, E-mail: nogueira@ufmt.br 